\title{
SUATU TINJAUAN TENTANG UPACARA MENUJUH BULAN KEHAMILAN (NYAKI TIHI) MENURUT ADAT DAYAK NGAJU DI MANDOMAI KECAMATAN KAPUAS BARAT KABUPATEN KAPUAS
}

\author{
Patricia $^{1}$, Herry Mantir ${ }^{2}$, Triyani $^{3}$ \\ ${ }^{1,2,3}$ Prodi PPKn, Universitas Palangka Raya \\ Email : patriciaikat97@gmail.com ${ }^{1}$,herrymantir@fkip.upr.ac.id ${ }^{2}$,triyani@fkip.upr.ac.id ${ }^{3}$
}

\begin{abstract}
Abstrak:
Penelitian ini di lakukan untuk mengetahui Suatu Tinjauan Tentang Upacara Tujuh Bulan Kehamilan (Nyaki Tihi) Menurut Adat Dayak Ngaju di Mandomai Kecamatan Kapuas Barat Kabupaten Kapuas. Metode penelitian yang digunakan adalah metode kualitatif. Instrumen penelitian ini adalah meliputi : lembar observasi, wawancara, studi kepustakaan, dokumentasi. Teknik analisis dalam penelitian ini adalah pengumpulan data,reduksi data,penyajian data atau display data, kemudian penarikan kesimpulan atau verifikasi data. Makna Nyaki Tihi adalah makna keselamatan bagi ibu hamil yang sedang mengandung anak pertama pada usia kehamilan tujuh bulan serta memberikan perlindungan dari ganguan roh jahat yang kemungkinan akan mengganggu proses kehamilan sampai selamat pada tapan melahirkan nantinya. Tata cara Nyaki Tihi ada beberapa hal yang harus di persiapkan yang terpenting kesiapan dari ibu hamil lalu selanjutnya melengkapi syarat yang di perlukan seperti babi atau ayam, tikar, gong, beras, tampung tawar, sesajen, hampatung sadiri, wadai (kue), nasi, telor. pertama di lakukan menyaki ibu hamil.Kedua yaitu pemercikkan air tampung tawar.Ketiga menabur beras Keempat menyiapkan sesajen dan hampatung sadiri. Kelima Kepala Adat mengucapkan mantra-mantra. Keenam atau yang terakhir ancak di larutkan ke sungai. Persyaratan Nyaki Tihi terdiri dari 14 yaitu, gong, tikar, sesajen, telor, ayam, sangku, beras, kelapa, kain putih, jarum, minyak harum, giling pinang, rokok, dan uang logam yang akan dipenuhi oleh seorang yang melakukan upacara Nyaki Tihi.
\end{abstract}

Kata Kunci: Upacara; Menujuh Bulan Kehamilan; Nyaki Tihi; Dayak Ngaju

\section{Abstract}


This study was done to determine An Overview On Ceremony Seven Months of Pregnancy (Nyaki Tihi) According to Dayak Ngaju in Mandomai District of West Kapuas Kapuas. The method used is a qualitative method. The research instruments are included: observation sheets, interview, literature study, documentation. The data in this study are data collection, data reduction, data presentation, or display the data and then drawing conclusions or data verification. Tihi Nyaki meaning is the meaning of safety for pregnant women pregnant with their first child at the age of seven months of pregnancy and provide protection from evil spirits disorder which is likely to interfere with the process of pregnancy through childbirth safely at different stages later. The procedure for Nyaki Tihi there are some things that must be prepared paramount readiness of pregnant women and subsequently completing the requirements that need such as pork or chicken, mats, gong, rice disposed of bargaining, offerings, hampatung sadiri, wadai (cake), rice, eggs. The first is done menyaki mother hamil.Kedua namely water capacity pemercikkan tawar.Ketiga Fourth prepare rice sowing and hampatung sadiri offerings. Fifth Head of Indigenous spells. Sixth or the last rack dissolved into the river. Tihi Nyaki requirements consist of 14 ie, gong, mats, offerings,

Keywords: Ceremony; Seven Months of Pregnancy; Nyaki Tihi; Ngaju Dayak

\section{A. PENDAHULUAN}

Kehamilan merupakan momen penting dalam perjalanan hidup manusia. Kehamilan juga menjadi langkah awal untuk memiliki buah hati, juga sebagai tujuan utama sebuah perkawinan. Kehamilan juga merupakan proses alamiah yang dialami kaum wanita sehingga akan membuat perubahan fisik maupun psikis. Namun pada dasarnya kehamilan tersebut bisa membuat para ibu merasa tidak nyaman, merasa risih serta sering berhati-hati dalam bergerak karena kandungan janin yang dibawanya, akan tetapi tidak semua pasangan selalu dikarunia atau di berikan anak oleh sang pencipta. Maka dari itu sebagai ungkapan syukur terhadap kehamilan dari anak pertama ada tradisi yang dilakukan oleh masyarakat Dayak Ngaju dalam menginjak usia kehamilan Menujuh bulan(Widyana, 2018).

Secara umum tradisi Menujuh bulan kehamilan pada setiap kampung yang berada di Kalimantan Tengah mempunyai cara masing-masing oleh karena itu cara tersendiri berdasarkan budaya leluhur masa lalu yang secara dominan mengandung nilai moral, etika, dan religius. Tradisi Menujuh bulan kehamilan atau dalam bahasa Dayak Ngaju Nyaki Tihi merupakan upacara menujuh bulanan kehamilan bagi seorang ibu yang mengandung anak pertama yang dilaksanakan untuk memperingati umur kehamilan pada bulan ke tujuh yang didalamnya mengandung nilai-nilai religius baik dari perilaku, peristiwa proses upacaranya. Pada masyarakat Dayak Ngaju, moral atau budi pekerti dijadikan acuan dalam segala tindakan dalam kehidupan. Upacara Menujuh bulan kehamilan Nyaki Tihi masih dilakukan sebagian besar masyarakat di Kecamatan Kapuas Barat adalah salah satu daerah yang masyarakatnya masih menjalankan tradisi Nyaki Tihi secara terus-menerus terutama bagi ibu yang mengandung anak pertama(Marjanto, 2011).

Budaya masyarakat di Kecamatan Kapuas Barat pada masa modern ini didominasi oleh masyarakat yang tingkat pendidikan, pekerjaan dan kultur sosialnya beragam. Sehingga, banyak dari anggota masyarakat melakukan tradisi Nyaki Tihi hanya sebatas 
mengikuti wasiat leluhur dan upacara biasa yang sekedarnya, tanpa memahami makna pada tradisi Nyaki Tihi.

Secara prinsip, tradisi Nyaki Tihi tidak terlepas dari nilai-nilai religus pada setiap urutan acaranya, khususnya nilai-nilai ajaran Dayak Ngaju tidak bisa dipisahkan dari ajaran budi pekerti yang terdapat pada sikap dan perilaku masyarakat Dayak yang melekat dengan istilah Bajenta tuntang bajurah dan sebagai cerminan huma betang. Nilai-nilai religius pada upacara Nyaki Tihi memiliki makna yang mendalam bagi seorang ibu yang pertama kali mengandung atau Temei. Menurut kepercayaan Suku Dayak Ngaju ibu tersebut sering mendapat gangguan roh - roh halus oleh karena itu dilakukanlah upacara Nyaki Tihi dengan tujuan untuk menjauhkan dari gangguan roh jahat yang kemungkinan bisa mengganggu kehamilan dengan jalan upacara Nyaki Tihi(Sunarningsih, 2018).

\section{B. KAJIAN TEORI}

Istilah Nyaki Tihi berasal dari dua kata yang secara subtansi berbeda makna. "Nyaki" dapat disamakan dengan "mamalas" yang secara literal berarti "mengoleskan", sedangkan "Tihi" adalah "hamil" atau "mengandung". Jadi jika dideskripsikan, Nyaki Tihi memiliki pengertian sebagai kegiatan atau tindakan "memoles ibu hamil". Berdasarkan penjelasan Nirwana Dalam Wilson (2009 : 43), Nyaki Tihi disebut juga dengan istilah "Ehet", yaitu upacara atau kegiatan tradisi dalam masyarakat Dayak Ngaju terhadap seorang perempuan yang sedang hamil anak pertama atau Temei (bahasa Dayak Ngaju). Sedangkan menurut buku yang ditulis Tjilik Riwut, dijelaskan bahwa "Nyaki" sama dengan mamalas, yaitu mengoleskan darah binatang pada tempat tertentu di tubuh seseorang dengan jari telunjuk (Tjilik Riwut, 1979:346). Berdasarkan beberapa fakta di atas, pengertian Nyaki Tihi adalah memoleskan darah kepada seorang perempuan yang sedang mengandung atau hamil anak pertama dalam masyarakat Dayak Ngaju.

Hakikat Nyaki Tihi dapat diperhatikan dari beberapa perspektif sesuai pengertiannya. Karena itu, hakikat Nyaki Tihi dalam konteks ini adalah: Pertama, Nyaki Tihi menempatkan istilah mamalas sebagai kata kunci. Karena itu, Nyaki Tihi adalah tindakan mengoleskan darah binatang tertentu (babi atau ayam kampung) ke bagian tubuh perempuan yang sedang mengandung. Kedua, Nyaki Tihi menempatkan media "darah" sebagai unsur kunci dalam upacara. Darah binatang dipakai sebagai media atau alat kelengkapan utama Nyaki Tihi. Ketiga, wanita hamil anak pertama dan di usia kehamilan ketujuh bulan sebagai objek pelaksanaan upacara adat Nyaki Tihi. Keempat, hal tersebut merupakan upaya keselamatan, menenteramkan, dan menjauhkan dari bahaya, serta menghindarkan dari gangguan roh jahat.

Nyaki Tihi berasal dari dua suku kata yaitu kata dasar Tihi dan Nyaki Tihi artinya Kandung, Batihi, mengandung, bunting, hamil, atau mimbit arep Offeny (2013:399). Jadi yang dimaksud dengan "Nyaki" dapat disamakan dengan "Mamalas" yang secara literal berarti "Mengoleskan", sedangkan "Tihi" adalah "hamil" atau "mengandung". Jadi jika dideskripsikan, Nyaki Tihi memiliki pengertian sebagai kegiatan atau tindakan "Memoles" ibu hamil. Nyaki Tihi merupakan upacara atau kegiatan tradisi dalam masyarakat terhadap seorang perempuan yang sedang hamil anak pertama atau Temei (bahasa Dayak Ngaju).

Menurut Tjilik Riwut (1979:56) Umumnya, apabila seorang wanita baru menikah atau sewaktu ia sedang hamil dan juga kalau ia baru rnelahirkan, maka saat itulah ada- 
rohaniah sangat lemah dan gampang sekali terpengaruh oleh kekuatan-kekuatan di luar dirinya. Sebab itu dalam keadaan demikian ia harus mentaati syarat-syarat tertentu demi melindungi dirinya dari bahaya.

Upacara adat Nyaki Tihi memiliki latar belakang pelaksanaan yang khas sebagai mana upacara adat-istidat lainnya di kalangan Suku Dayak secara umum di Mandomai Kecamatan Kapuas Barat Kabupaten Kapuas, upacara itu dilatarbelakangi oleh beberapa hal. Pertama, keyakinan atau kepercayaan terhadap perlindungan dan keselamatan ibu yang hamil, sehingga upacara adat Nyaki Tihi merupakan semacam perlindungan terhadap ibu yang mengandung bayi pertama (Temei). Uniknya, upacara itu hanya dilakukan untuk kandungan bayi pertama. Terhadap kandungan bayi kedua dan seterusnya tidak lagi. Kedua, kepercayaan bahwa seorang ibu yang hamil memiliki masa lemah di bulan tertentu. Kepercayaan itu kemudian memunculkan ritus atau upacara adat Nyaki Tihi yang dilakukan ketika ibu hamil memasuki bulan ketujuh masa kandungannya. Hal itu disebabkan keyakinan bahwa ibu hamil dalam bulan tersebut mengalami kelemahan secara rohaniah. Ketiga, kepercayaan kepada "darah" sebagai media penenteram atau media yang memiliki "kuasa" mengusir pengaruh roh-roh jahat. Berdasarkan kepercayaan itu, sarana penting yang digunakan dalam upacara adat Nyaki Tihi adalah darah sebagai alat manyaki atau mamalas yang diambil dari binatang babi atau ayam kampung yang dikorbankan dalam upacara tersebut. Darah sebagai sarana manyaki atau mamalas di sini dipandang dapat meredam bahaya atau celaka dan menjauhkan dari roh-roh yang jahat yang dapat mengganggu kandungan yang akan dilahirkan (Manyadingen). Dengan demikian, upacara Nyaki Tihi dilakukan dengan latar belakang peristiwa-peristiwa sulit yang dihadapi seorang perempuan saat melahirkan anak pertama. Bila saat lemah itu tidak dijaga, roh perempuan Temei tersebut mudah diganggu kuasa jahat atau kuntilanak dalam bahasa Dayak Ngaju hantuen baduruk(Sihung, 2019).

\section{METODE PENELITIAN}

Lokasi penelitian ini dilaksanakan di Mandomai Kecamatan Kapuas Barat Kabupaten Kapuas. Jenis penelitian ini adalah penelitian kualitatif. Pengumpulan data yang digunakan dalam penelitian ini adalah sebagai berikut: observasi, wawancara, studi kepustakaan dan dokumentasi. Sedangkan teknik penggunaannya dapat dijelaskan sebagai berikut : Observasi, Wawancara, Studi Kepustakaan, Dokumentasi. Penelitian ini menggunakan teknik analisis data kualitatif, data di olah sehingga dapat di ambil kesimpulan atau makna yang valit, serta metode yang sebaiknya untuk menganalisis data kualitatif agar dapat memenuhi syarat ilmiah dalam penelitian.

\section{HASIL DAN PEMBAHASAN}

1. Makna upacara Menujuh bulan kehamilan Nyaki Tihi menurut adat Dayak Ngaju di Mandomai Kecamatan Kapuas Barat Kabupaten Kapuas .

Makna Nyaki Tihi adalah makna keselamatan bagi ibu hamil yang sedang mengandung anak pertama pada usia kehamilan tujuh bulan serta memberikan perlindungan dari gangguan roh jahat yang kemungkinan akan mengganggu proses kehamilan sampai selamat pada tahapan melahirkan nantinya. Upacara Nyaki Tihi dilakukan pada usia kehamilan tujuh bulan pada ibu hamil yang mengandung anak pertama (temei) dengan tujuan memberikan doa keselamatan bagi orang yang 
melaksanakan upacara Nyaki Tihi terutama bagi ibu hamil dalam kehamilan pertama. Maka sosial budaya menjalin kekerabatan dalam sebuah perbedaan agama masing masing tanpa membedakan agama acara ini dilakukan atas dasar keyakinan setiap anggota masyarakat yang melakukan kegiatan Nyaki Tihi sehingga aspek religiusnya adalah menjalankan hakikat dan sariat dalam sebuah kepercayan nenek moyang dari dulu sampai sekarang. Nilai - nilai budaya dalam upacara Nyaki Tihi adalah budaya Orang dayak ngaju yang tidak bisa ditinggal kan karena itu adalah peninggalan leluhur, yang wajib dilakukan bagi setiap masyarakat yang mempunyai keturunan Suku Dayak Ngaju Asli.

Tradisi Nyaki Tihi adalah upacara adat khusus bagi ibu hamil dalam kehamilan anak pertama atau Temei bagi masyarakat adat dayak ngaju asli, sehingga setiap masyarakat suku dayak ngaju selalu melakukan upacara nyaki tihi, ini dilakukan karena tradisi nilai - nilai budaya dari leluhur dari aspek sosial, kami mengundang masyarakat sekitar dalam kegiatan upacara Nyaki Tihi dengan tujuan menjalin kekeluargaan dalam upacara itu, secara tidak langsung memberitahu bahwa sebantar lagi si ibu mau melahirkan diminta mohon bantuan doa untuk kelancaran selama mengandung sampai proses melahirkan. Tradisi Nyaki Tihi dilaksanakan kapan dilaksanakan belum jelas namun adat Nyaki Tihi ini adalah tradisi yang ada sejak lama namun sudah mulai jarang dilakukan sebab beberapa masyarakat sudah melakukan perkawinan camupuran budaya sehingga tradisi ini bagi sebagian masyarakat mulai ditinggalkan, akan tetapi bagi masyarakat turunan asli Dayak Ngaju mereka selalu melakukan upacara Nyaki Tihi bagi ibu hamil yang mengandung pada anak pertama.

\section{Tata cara Nyaki Tihi di Mandomai Kecamatan Kapuas Barat Kabupaten Kapuas}

Upacara Nyaki Tihi memiliki beberapa tata cara di Mandomai atau Kecamatan Kapuas Barat yakni pertama dulu di sediakan tikar dari rotan, setelah itu di atas tikar ada Gong yang di duduki oleh ibu hamil setelah itu baru di lakukan menyaki orang yang hamil itu. Pertama, cara menyakinya yaitu dengan memotong hewan seperti babi atau ayam untuk di ambil darahnya lalu di oleskan pertama dari perut , lalu dari dada, dan di kening. Kedua, lalu di percik air tampung tawar setelah selesai percikan air tampung tawar. Ketiga, lalu beras di tabur di atas kepala maksudnya supaya ibu hamil setelah melahirkan mendapat rejeki dan ada juga beras putih di tabur di beberapa penjuru. Keempat, ada sesajen dan ada juga hampatung sadiri namanya. Kegunaan hampatung sadiri itu adalah untuk mengganti orang yang hamil tujuh bulan itu. Jadi di dalam hampatung sadiri itu ada di buat tempatnya yang di namakan "ancak" . Di dalam ancak itu berupa sesajen, wadai, nasi, ada juga telur. Kelima, kepala adat mengucapkan mantra-mantra di dalam hampatung sadiri itu lalu yang hamil meludah hampatung sadiri dan menolaknya dengan tangan kiri. Maksudnya menolak, agar menolak marabahaya supaya ibu hamil itu tidak bisa kena roh-roh jahat atau pengaruh-pengaruh yang tidak di kehendaki. Keenam, ancak di bawa ke sungai lalu di larutkan. Maksud dan tujuannya supaya roh-roh yang ada di dalam air memberikan perlindungan untuk ibu hamil yang mengandung tujuh bulan itu agar melahirkan anak yang sempurna dan tidak ada menemui apa-apa ataupun kelainan.

Ugang (1983: 41), ” Pembauran nilai - nilai agama yang dianggap luhur seperti itu tentu saja tidak terjadi sekejap mata melainkan melainkan melalui proses yang 
terjadi dalam peristiwa heroik yang bersejarah dan terjadi pada zaman tertentu di masa silam ”. Rina Teriasi (1997: 22) mengatakan:"setiap upacara adat dan ritus agama yang mempersembahkan korban, darahnya tidak dibuang tetapi digunakan untuk pemercikkan dan pemolesan. Misalnya untuk "Manyaki atau Mamalas".

\section{Persyaratan upacara menujuh bulan kehamilan Nyaki Tihi menurut adat Dayak} Ngaju di Mandomai Kecamatan Kapuas Barat Kabupaten Kapuas.

Upacara Nyaki Tihi memerlukan beberapa syarat yakni termasuk ada tikar, Gong, dan ada juga syaratnya sesajen, telur, ayam atau babi kalau mampu setelah itu ada panduduknya. Panduduk itu dalam sangku berisi beras, di dalam beras itu di taruh kelapa, yang di lilit dengan kain putih bersamaan dengan jarum, telur, minyak harum, giling pinang, rokok dengan uang logam. Uang logam tersebut tidak di tentukan besar dan kecilnya yang penting ada.

Menurut Rina Teriasi (1997 22): Karena pada saat darah dioleskan ke objek, maka roh yang didalam darah itu akan menyampaikan ayat-ayat atau doa yang diucapkan oleh orang-orang yang manyaki kepada Ranying Hatala Langit, sehingga apa yang diharapkan akan diterima dan dikabulkan oleh Ranying Hatala langit. Oleh karena itu perlakukan terhadap ibu hamil sangatlah selalu diperhatikan setiap langkahnya terutama bagi ibu hamil yang mengandung anak pertama atau Temei. Mulai dari berbicara, berpakaian, bercangkarama semua ada aturun supaya ibu hamil tersebut selamat dan tidak mendapat mala petaka ketika proses melahirkan nantinya.

\section{PEMBAHASAN}

\section{Makna upacara Nyaki Tihi}

Hasil penelitian dilapangan diperoleh data tentang makna Nyaki Tihi, tata cara Nyaki Tihi, persyaratan Nyaki Tihi menurut adat Dayak Ngaju di Mandomai Kecamatan Kapuas Barat Kabupaten Kapuas. Makna Nyaki Tihi adalah makna keselamatan bagi ibu hamil yang sedang mengandung anak pertama pada usia kehamilan tujuh bulan serta memberikan perlindungan dari gangguan roh jahat yang kemungkinan akan mengganggu proses kehamilan sampai selamat pada tahapan melahirkan nantinya. Upacara Nyaki Tihi dilakukan pada usia kehamilan tujuh bulan pada ibu hamil yang mengandung anak pertama (temei) dengan tujuan memberikan doa keselamatan bagi orang yang melaksanakan upacara Nyaki Tihi terutama bagi ibu hamil dalam kehamilan pertama. Maka sosial budaya menjalin kekerabatan dalam sebuah perbedaan agama masing - masing tanpa membedakan agama acara ini dilakukan atas dasar keyakinan setiap anggota masyarakat yang melakukan kegiatan Nyaki Tihi sehingga aspek religiusnya adalah menjalankan hakikat dan sariat dalam sebuah kepercayan nenek moyang dari dulu sampai sekarang. Nilai - nilai budaya dalam upacara Nyaki Tihi adalah budaya Orang dayak ngaju yang tidak bisa ditinggal kan karena itu adalah peninggalan leluhur, yang wajib dilakukan bagi setiap masyarakat yang mempunyai keturunan Suku Dayak Ngaju Asli.

Tradisi Nyaki Tihi adalah upacara adat khusus bagi ibu hamil dalam kehamilan anak pertama atau Temei bagi masyarakat adat dayak ngaju asli, sehingga setiap masyarakat suku dayak ngaju selalu melakukan upacara nyaki tihi, ini dilakukan 
karena tradisi nilai - nilai budaya dari leluhur dari aspek sosial, kami mengundang masyarakat sekitar dalam kegiatan upacara Nyaki Tihi dengan tujuan menjalin kekeluargaan dalam upacara itu, secara tidak langsung memberitahu bahwa sebantar lagi si ibu mau melahirkan diminta mohon bantuan doa untuk kelancaran selama mengandung sampai proses melahirkan. Tradisi Nyaki Tihi dilaksanakan kapan dilaksanakan belum jelas namun adat Nyaki Tihi ini adalah tradisi yang ada sejak lama namun sudah mulai jarang dilakukan sebab beberapa masyarakat sudah melakukan perkawinan camupuran budaya sehingga tradisi ini bagi sebagian masyarakat mulai ditinggalkan, akan tetapi bagi masyarakat turunan asli Dayak Ngaju mereka selalu melakukan upacara Nyaki Tihi bagi ibu hamil yang mengandung pada anak pertama.

\section{Tata cara Nyaki Tihi di Mandomai}

Di katakan tata cara Manyaki Tihi di Mandomai atau Kecamatan Kapuas Barat pertama dulu di sediakan tikar dari rotan, setelah itu di atas tikar ada Gong yang di duduki oleh ibu hamil setelah itu baru di lakukan menyaki orang yang hamil itu. Pertama, cara menyakinya yaitu dengan memotong hewan seperti babi atau ayam untuk di ambil darahnya lalu di oleskan pertama dari perut, lalu dari dada, dan di kening. Kedua, lalu di percik air tampung tawar setelah selesai percikan air tampung tawar. Ketiga, lalu beras di tabur di atas kepala maksudnya supaya ibu hamil setelah melahirkan mendapat rejeki dan ada juga beras putih di tabur di beberapa penjuru Keempat, ada sesajen dan ada juga hampatung sadiri namanya. Kegunaan hampatung sadiri itu adalah untuk mengganti orang yang hamil tujuh bulan itu. Jadi di dalam hampatung sadiri itu ada di buat tempatnya yang di namakan "ancak" . Di dalam ancak itu berupa sesajen, wadai, nasi, ada juga telur. Kelima, kepala adat mengucapkan mantra-mantra di dalam hampatung sadiri itu lalu yang hamil meludah hampatung sadiri dan menolaknya dengan tangan kiri. Maksudnya menolak, agar menolak marabahaya supaya ibu hamil itu tidak bisa kena roh-roh jahat atau pengaruh-pengaruh yang tidak di kehendaki. Keenam, ancak di bawa ke sungai lalu di larutkan. Maksud dan tujuannya supaya roh-roh yang ada di dalam air memberikan perlindungan untuk ibu hamil yang mengandung tujuh bulan itu agar melahirkan anak yang sempurna dan tidak ada menemui apa-apa ataupun kelainan. Ugang (1983: 41), " Pembauran nilai - nilai agama yang dianggap luhur seperti itu tentu saja tidak terjadi sekejap mata melainkan melainkan melalui proses yang terjadi dalam peristiwa heroik yang bersejarah dan terjadi pada zaman tertentu di masa silam ”. Rina Teriasi (1997: 22) mengatakan:"setiap upacara adat dan ritus agama yang mempersembahkan korban, darahnya tidak dibuang tetapi digunakan untuk pemercikkan dan pemolesan. Misalnya untuk "Manyaki atau Mamalas"

\section{Persyaratan Nyaki Tihi}

Di katakan bahwa syarat-syaratnya termasuk ada tikar, Gong, dan ada juga syaratnya sesajen, telur, ayam atau babi kalau mampu setelah itu ada panduduknya. Panduduk itu dalam sangku berisi beras, di dalam beras itu di taruh kelapa, yang di lilit dengan kain putih bersamaan dengan jarum, telur, minyak harum, giling pinang, rokok dengan uang logam. Uang logam tersebut tidak di tentukan besar dan kecilnya yang penting ada. Menurut Rina Teriasi (1997 22): Karena pada saat darah dioleskan 
ke objek, maka roh yang didalam darah itu akan menyampaikan ayat-ayat atau doa yang diucapkan oleh orang-orang yang manyaki kepada Ranying Hatala Langit, sehingga apa yang diharapkan akan diterima dan dikabulkan oleh Ranying Hatala langit. Oleh karena itu perlakukan terhadap ibu hamil sangatlah selalu diperhatikan setiap langkahnya terutama bagi ibu hamil yang mengandung anak pertama atau Temei. Mulai dari berbicara, berpakaian, bercangkarama semua ada aturun supaya ibu hamil tersebut selamat dan tidak mendapat mala petaka ketika proses melahirkan nantinya.

\section{E. KESIMPULAN}

Kesimpulan dari penelitian tentang "Upacara Menujuh Bulan Kehamilan (Nyaki Tihi) Menurut Adat Dayak Ngaju” adalah 1). Makna Nyaki Tihi merupakan keselamatan bagi ibu hamil yang sedang mengandung anak pertama pada usia kehamilan tujuh bulan serta memberikan perlindungan dari gangguan roh jahat yang kemungkinan akan mengganggu proses kehamilan sampai selamat pada tahapan melahirkan nantinya. 2). Upacara Nyaki Tihi memiliki beberapa tata cara di Mandomai atau Kecamatan Kapuas Barat yakni pertama dulu di sediakan tikar dari rotan, setelah itu di atas tikar ada Gong yang di duduki oleh ibu hamil setelah itu baru di lakukan menyaki orang yang hamil itu. Pertama, cara menyakinya yaitu dengan memotong hewan seperti babi atau ayam untuk di ambil darahnya lalu di oleskan pertama dari perut, lalu dari dada, dan di kening. Kedua, lalu di percik air tampung tawar setelah selesai percikan air tampung tawar. Ketiga, lalu beras di tabur di atas kepala maksudnya supaya ibu hamil setelah melahirkan mendapat rejeki dan ada juga beras putih di tabur di beberapa penjuru. Keempat, ada sesajen dan ada juga hampatung sadiri namanya. Kegunaan hampatung sadiri itu adalah untuk mengganti orang yang hamil tujuh bulan itu. Jadi di dalam hampatung sadiri itu ada di buat tempatnya yang di namakan "ancak" . Di dalam ancak itu berupa sesajen , wadai , nasi, ada juga telur. Kelima, kepala adat mengucapkan mantra-mantra di dalam hampatung sadiri itu lalu yang hamil meludah hampatung sadiri dan menolaknya dengan tangan kiri. Maksudnya menolak, agar menolak marabahaya supaya ibu hamil itu tidak bisa kena roh-roh jahat atau pengaruh-pengaruh yang tidak di kehendaki. Keenam, ancak di bawa ke sungai lalu di larutkan. Maksud dan tujuannya supaya roh-roh yang ada di dalam air memberikan perlindungan untuk ibu hamil yang mengandung tujuh bulan itu agar melahirkan anak yang sempurna dan tidak ada menemui apa-apa ataupun kelainan. 3). Upacara Nyaki Tihi memerlukan beberapa syarat yakni termasuk ada tikar, Gong, dan ada juga syaratnya sesajen, telur, ayam atau babi kalau mampu setelah itu ada panduduknya. Panduduk itu dalam sangku berisi beras, di dalam beras itu di taruh kelapa, yang di lilit dengan kain putih bersamaan dengan jarum, telur, minyak harum, giling pinang, rokok dengan uang logam. Uang logam tersebut tidak di tentukan besar dan kecilnya yang penting ada.

\section{F. SARAN DAN UCAPAN TERIMA KASIH}

Berdasarkan pada kesimpulan tersebut di atas, kiranya dapatlah penulis ajukan saran-saran sebagai berikut : 
1. Sebaiknya tradisi adat Nyaki Tihi harus di lestarikan oleh generasi muda agar dapat mempertahankan adat dan budaya yang sudah turun-temurun ke generasi selanjutnya di era modern ini.

2. Sebaiknya tokoh adat atau masyarakat di Mandomai Kecamatan Kapuas Barat Kabupaten Kapuas yang masih memiliki keturunan adat Nyaki Tihi dapat mensosialisasikan kepada generasi muda tentang makna, tata cara, dan persyaratan upacara adat Nyaki Tihi.

3. Sebaiknya damang atau mantir adat mensosialisasikan adat Nyaki Tihi agar tetap dapat di lestarikan oleh masyarakat Mandomai Kecamatan Kapuas Barat Kabupaten Kapuas.

4. Sebaiknya Nyaki Tihi harus tetap di lestarikan sebagai budaya turun-temurun dari nenek moyang.

5. Sebaiknya tokoh adat dan masyarakat dapat memperkenalkan tradisi Nyaki Tihi sejak dini dengan mengajak anak-anak ke upacara tradisi Nyaki Tihi.

\section{REFERENSI}

Eddy dan Helmuth, 2013. Metodologi Penelitian Kualitatif. Surabaya: Jenggala PustakaUtama

Ica Vonari, 2018. Makna Upacara Nyaki Ehet Adat Dayak Maanyan Di Desa Saka Pinang Kapuas Kalimantan Tengah.Jurnal Ilmiah.

Marjanto, D. K. (2011). Kaharingan: Perjuangan Masyarakat Adat Dayak Ngaju di Kabupaten Kotawaringin Timur, Dahulu dan Sekarang. In Buku Kearifan Lokal di Tengah Modernisasi. https://doi.org/10.16194/j.cnki.31-1059/g4.2011.07.016

NilaRiwut, 2003. Maneser Panatau Tatu Hiang, Menyelami Kekayaan Leluhur, Pusaka Lima, Yogyakarta,

Sihung, S. S. (2019). PESAN MORAL DALAM MITOS PERKAWINAN LELUHUR DAYAK NGAJU. Dharma Duta. https://doi.org/10.33363/dd.v15i1.157

Sugiyono, 2009 .Metode Penelitian Pendidikan Pendekatan Kuantitatif, Kualitatif, dan R E D Alpabeta Bandung

Sunarningsih, S. (2018). KUTA HANTAPANG, BENTENG MASYARAKAT NGAJU DI KALIMANTAN TENGAH. Kindai Etam: Jurnal Penelitian Arkeologi. https://doi.org/10.24832/ke.v3i1.13

Teriasi, Rina, 1997."Makna Darah dalam Upacara Pemulihan Adat", skripsi, STAHN

Wilson, 2009.Makna Upacara Nyaki Tihi Adat Dayak Ngaju Di Desa Samba Danum Katingan, Kalimantan Tengah. Jurnalllmiah Vol.26

Widyana, I. K. (2018). PENDIDIKAN AGAMA HINDU BERBASIS KEARIFAN LOKAL KAHARINGAN MELALUI MATA KULIAH TAWUR DI SEKOLAH TINGGI AGAMA HINDU NEGERI TAMPUNG PENYANG PALANGKA RAYA. Dharmasmrti: Jurnal Ilmu Agama Dan Kebudayaan. https://doi.org/10.32795/ds.v9i2.152

Wood, J. T. Sukadi, (2012). Komunikasi Teoridan Praktik. Jakarta Selatan: Salemba Humanika. 